\title{
Students' factors affecting undergraduates' perceptions of their teaching and learning process within ECTS experience
}

\author{
Jesús De la Fuente ${ }^{*}$, María Cardelle-Elawar ${ }^{2}$, F Javier Peralta ${ }^{1}$, M. Dolores Sánchez ${ }^{1}$, José Manuel \\ Martínez-Vicente ${ }^{1}$ and Lucía Zapata ${ }^{1}$
}

\author{
Department of Educational and Developmental Psychology, Faculty of Psychology, University of Almería, Almería, Spain \\ 2 Division of Educational Leadership and Innovation, Arizona State University, Glendale, AZ, USA
}

\section{Edited by:}

M. Kloep, University of Glamorgan, UK

\section{Reviewed by:}

Ying Xie, Lewis University, USA

Figen Cok, Baskent University, Turkey

*Correspondence:

Jesús De la Fuente, Department of

Educational and Developmental

Psychology, Faculty of Psychology,

University of Almería, Carretera de

Sacramento s/n, 04120 La Cañada de

San Urbano, Almería, Spain.

e-mail:jfuente@ual.es
Introduction: In the present study, we investigated the potential factors that influenced the level of students satisfaction with the teaching-learning process (TLP), from the perspective of students participating in the European Credit Transfer System (ECTS) experience. Method: A total of 1490 students from the Universities of Almería and Granada (Spain) participated in an evaluation of their class discipline area. They completed the new revised protocol for evaluating the ECTS experience. Analyses of variance were carried out, taking the following factors as independent variables: student's grade average, year in school, study discipline, credit load in terms of ECTS credits assigned to a subject, the e-learning approach. Perception of theTLP was used as the dependent variable. Results: The data analyses showed variability of the degree of statistically significance among the factors that influenced students' perceptions of the TLP. These factors included: Student's grade average (in favor of high performers), year in school (in favor of earlier years), ECTS load (in favor of subjects with a medium load of credits), and e-learning (in favor of its use). These research findings provided evidence to explore the delineation of a potential profile of factors that trigger a favorable perception of the TLP. Discussion and Conclusion: The present findings certainly have implications to deepen our understanding of the core beliefs, commitment, and the experience in shaping the implementation of the European Higher Education Area through the ECTS.

Keywords: teaching-learning perception, European Higher Education Area, satisfaction with teaching, satisfaction with learning

\section{INTRODUCTION}

There is a need to study the interaction of teaching and learning processes (TLPs) in formal educational contexts. There are three major reasons to support this interrelated view of the two processes. First, these are formal psychological processes. In other words, they do not appear spontaneously, as in non-formal or informal contexts; instead, the processes are put into play based on certain parameters of systematic decision making. For example, in Spain, these programmed decisions are found in the Instructional Plans prepared for each class discipline area; these plans become the basis for how the TLP unfolds. Given their importance, a great deal of time and effort has gone into preparation of these Plans at the university level (De Miguel, 2006). Second, given the two-fold nature of the process (teaching-learning), we take the metaphor of vectors and speak of the directionality of each process: the two processes may point in the same direction, or in different or even opposite directions. There is a convergence of different types of learning processes (self-regulated/ deep vs. not self-regulated/surface) with different types of teaching processes (regulatory vs. non-regulatory). Consequently, different end products are produced (satisfactory vs. unsatisfactory) in a combined, interactive fashion, as recent evidence has shown (Abar and Loken, 2010). Third, since the two-fold process is systemic and interactive, whatever takes place in one of the processes affects how the other process develops, so that the two must be considered to be in an interdependent relationship.
The major concern is to articulate our understanding how the development of the teaching process necessarily affects the learning process and vice versa (De la Fuente and Justicia, 2007; García-Berbén et al., 2007). This concern has not been overlooked in present-day experimentation within the European Higher Education Area (EHEA) and the European Credit Transfer System (ECTS), and in the analysis of advances and innovations within the TLP. Although recent studies have focused on this question, specifying different factors that can affect the widespread implementation of this educational model, including integrated systems of continuous assessment and ICT (Coll et al., 2007), university teaching innovation (Méndez, 2005; Tirado et al., 2006), and the degree of competency acquisition in university students (Solanes et al., 2008). However, this generalization has not always been supported by evidence that corroborates whether the changes are being produced in the right direction. For example, one question worth analyzing is whether students' perception of the quality of teaching processes is accurate, and whether this teaching is accompanied by a quality learning process. In fact, this assessment parameter underlies any system for evaluating university quality. In Spain, for example, this aspect is at the core of teacher assessment in the Program on Teaching (Ministry of Education, 2010).

Students of Higher Education through their experience of the TLP, may receive three different types of instruction (De la Fuente, in press): Type (1) refers to instruction through the 
traditional lecture method. This approach is the formal presentation of the content by the instructor as a subject matter expert. The expected learning is based on understanding the concepts and is demonstrated through recall during student examination. It is characterized by a high proportion of lecture methodology where greater weight is given to conceptual learning, both in terms of workload and in grading. Type (2) refers to regulatory instruction. This approach includes three special components to enhance classroom performance: (a) students use metacognitive strategies for planning, monitoring, and modifying their cognition; (b) students experience active learning by managing and controlling their effort on classroom academic tasks; (c) students are exposed to different cognitive strategies such as rehearsal, elaboration, and organizational strategies to foster their active learning. Type (3) refers to instruction around autonomous learning. The instructor's expectation is that students are able to become in control of their learning by learning independently. The instructor behaves as a facilitator in helping students be responsible for their own learning environment. Students have the freedom to carry on learning discussions based on practical situations, thus encouraging applied professional competencies. This methodology is typical of experimentation in the EHEA, with equivalent weight given to the learning of skills and concepts, and an assessment system based on competencies (ECTS).

\section{THE DEDEPRO MODEL AS A BASIS FOR INTERACTIVE EVALUATION OF THE TEACHING-LEARNING PROCESS}

Establishing the variables that modulate the degree of satisfaction with one's experience of the TLP has been a constant theme in recent research on this topic. The 3P Model (PresageProcess-Product) from Biggs (2001) has established personal and contextual presage variables that are determining factors in undergraduate students' learning processes (Biggs et al., 2001). In complementary fashion, the DEDEPRO model, an acronym for DEsign-DEvelopment-PROduct (De la Fuente et al., 2005b; De la Fuente and Justicia, 2007), has offered evidence of numerous relationships between the presage variables and the design, development, and the end product of teaching and learning (Case and Gunstone, 2002; Zusho and Pintrich, 2003; Heikkila and Lonka, 2006; Schunk and Zimmerman, 2008). In this Model - from the student perspective - the design variables relate to preparation of learning behavior (being aware of and planning the learning process). The development variables relate to control activities and learning process execution (self-regulating behaviors, selfregulation strategies, self-assessment, and to the teaching process (regulatory teaching). The product variables relate to the closure of learning behaviors (satisfaction with teaching and learning, and performance).

There is significant evidence of the influence of students' personal self-regulation (presage variable) in how students perceive their performance (Zimmerman and Martinez-Pons, 1988; De la Fuente et al., 2008; Zimmerman, 2008; De la Fuente and Eissa, 2010). Recently, the variable of students' grade point average has been postulated as a presage variable with the potential to predict the learning process and later academic achievement (De la Fuente and Cardelle-Elawar, 2009; Cardelle-Elawar and Sanz de Acedo Lizarraga, 2010; De la Fuente et al., 2010a).
There is also evidence regarding the effect of certain contextrelated presage variables, such as year in school (De Miguel and Arias, 1999; Tejedor and García-Valcárcel, 2007) and the use of ICT systems in teaching (Bono et al., 2006; Borges et al., 2007; Montil et al., 2007; Correa and Paredes, 2009) - sometimes with rather unfavorable results (Mahdizadeh et al., 2008) in terms of the perception of the TLP.

Nonetheless, we need to progress in our understanding of the changes and adjustments that are taking place, in order to extrapolate to the current system of educational experimentation within the EHEA (ECTS).

\section{OBJECTIVES AND HYPOTHESES}

Based on the evidence from the above review of the literature, this investigation sought three major objectives by testing the following hypotheses to determine the degree to which different personal and contextual factors, as presage variables, affect students' perception of the TLP outcome. (1) Students' grade point average (low-mediumhigh), as a student-specific presage variable, will influence their level of satisfaction with the TLP. Based on previous evidence, it is expected that higher levels of student performance are accompanied by higher levels of satisfaction, and vice versa (Salanova et al., 2005; Caballero et al., 2007). (2) Year in School (years 1 and 2 vs. years 3 and 4; García and San Segundo, 2008) and the teaching approach use of e-learning vs. non-use of e-learning, as contextual presage variables, will also influence the satisfaction level with the TLP. (3) How the discipline area is designed in terms of its learning load in ECTS credits, light vs. medium vs. heavy, will influence the degree of satisfaction with the TLP. (4) There will be interactions among these factors. Thus, we expect an interaction between the students' presage and the contextual presage factors under consideration.

These hypothetical relationships are represented and framed within Biggs' 3P Model (Biggs, 2001) and within the DEDEPRO Model, Design-Development-Product (De la Fuente and Justicia, 2007), as they are illustrated in Figure 1.

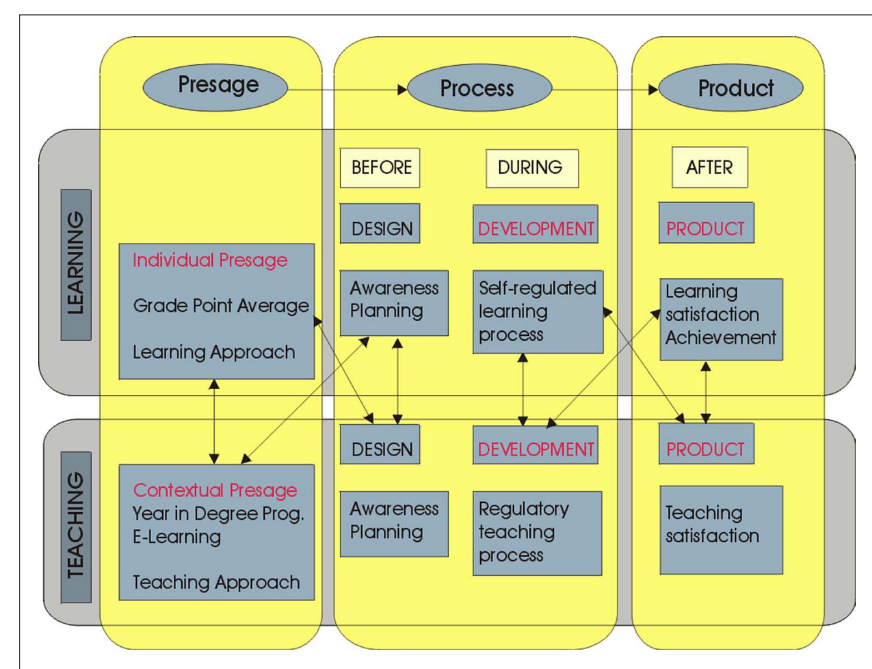

FIGURE 1 | Variables being studied in this investigation (in red), based on the 3P Model (Biggs, 2001) and the DEDEPRO Model (De la Fuente and Justicia, 2007). 


\section{MATERIALS AND METHODS PARTICIPANTS}

The sample was composed of 1490 undergraduate students from the Universities of Almería and Granada (Spain). The selection was made from seven degree programs in five different disciplines of study: 616 from social sciences, 265 from legal sciences, 443 from educational sciences, 34 from pure sciences, and 132 from health sciences. Of these, 850 were in their first year of the program of study, 224 in the second year, 173 in third year, and 228 in fourth year. As for gender, the sample contained 986 female students and 522 male students.

\section{DESIGN}

We used an ex post-facto design, making use of data from students' assessments after the fact. The five factors considered as independent variables were: students' grade point average, year in school, discipline of study, ECTS credits assigned to the subject, and use of the e-learning approach. The dependent variable was students' perceptions of the TLP.

\section{INSTRUMENTS}

We used the new version of the assessment Protocol for the ECTS experience (De la Fuente, 2009). This protocol, on the teacher's side, includes an appraisal of the instructional process design (teacher guide), of how teaching and learning developed (instructional action) and of output (students' satisfaction with teaching and learning). We assessed students' level of satisfaction of their performance with the scale Assessment of the Teaching-Learning Process (ATLP-S). This scale was selected because of its high reliability on previous studies (De la Fuente et al., 2005a,b, 2008). Recently, It was cross validated using the new version of the assessment Protocol for the ECTS experience with Spanish and British samples (De la Fuente et al., 2010b). This Likert-type scale contains 30 items and resulted in two independent scores for the TLPs, a combined score for the process as a whole, and 15 descriptors for each of the two processes (see Appendix). In the Spanish sample we obtained: Cronbach's alpha $=0.930$ (complete scale), 0.930 (first half), and 0.904 (second half). Spearman-Brown: 0.8439 and Guttman: 0.803. For the first subscale, teaching process: 0.96 (total), 0.93 (first half), and 0.92 (second half). In the second subscale, learning process: 0.94 (total), 0.93 (first half), and 0.88 (second half). For the British sample: Cronbach's alpha $=0.913$ (complete scale), 0.984 (first half), and 0.847 (second half). Spearman-Brown: 0.736 and Guttman: 0.732 . For the first subscale, teaching process: 0.88 (total), 0.83 (first half), and 0.80 (second half). In the second subscale, learning process: 0.85 (total), 0.80 (first half), and 0.73 (second half). Thus, the reliability rates of the ATLP-S can be considered acceptable.

\section{PROCEDURE}

During school year 2008-2009, students completed the new assessment ECTS protocol mentioned above at the end of each class subject, whether it was a semester or full-year course. Through their respective Vice President and their Unit of the EHEA, teachers were invited to participate along with their students in this TLP self-assessment. Participation would make it possible to obtain useful information for later participation in the Teaching Program (Ministry of Education, 2010). The assessment was carried out on a voluntary basis using a web utility called e-EEES, created for this purpose, in its Spanish and English versions (De la Fuente and Trujillo, 2008; www.education-psychology.com/eees).

\section{DATA ANALYSES}

We used cluster analysis to establish groups of students according to their performance (low, medium, and high levels of student performance). Similarly, cluster analysis was used to determine low, medium, and high groups according to a subject's credit load (in terms of ECTS). We used multivariate analyses of variance to establish interdependencies between independent and dependent variables. For the independent variable were the factors: student's grade point average, year in school, discipline of study, ECTS credits for the subject, and the use of e-learning teaching approach. In all analyses we used the TLP as the dependent variable.

\section{RESULTS}

The first analysis was conducted to investigate the influence of the factors grade point average, year in school, and e-learning, on the TLP students' perception. The results of the $3 \times 2$ factor interaction, level of performance, and year in school with TLP perception, showed a significant main effect only for the level of performance, whether considering the two processes jointly, $F(4.1228)=4.30, p<0.002$, or taking separately the teaching process, $F(2.614)=6.214, p<0.002$, and the learning process, $F(2.614)=7.73, p<0.000$. This effect confirmed that students' perception of their satisfaction at the performance level influence the TLP. Although not statistically significant, year in school also showed an effect, with regard to a lower perception of the teaching process, $F(1.614)=3.17, p<0.07$, during third and fourth years. The learning process did not show this effect. That is, students' perception of the teaching process changes as they progress to more advanced levels, but their perception of their learning process does not show to be significant (see Table $\mathbf{1}$ ).

The analysis of the $2 \times 3$ factor interaction, using e-learning teaching approach and level of students' performance with TLP perception, showed a significant main effect of e-learning approach, $F(2.467)=3.00 . p<0.05$, demonstrating a more favorable overall perception of class discipline areas taught using e-learning. E-learning also appeared to have a significant effect in assessment the teaching process, $F(1.468)=570, p<0.01$, but not in the learning process's perception. However, the effect of performance level on TLP students' perception disappears (see Table 2).

It is worth noting the largest differences on students' perceptions of the TLP effect in regard to the instructional approach in teaching, e-learning or face-to-face, $F(2.248)=2.45, p<0.08$ (Roy's largest root), The largest difference was found in low-performing students, while perception remains more or less equal in higher performing groups. This statistical effect can be interpreted in support of using e-learning in learning and teaching, especially for low-performing students. This effect is illustrated more clearly in Figures 2 and 3.

\section{THE SUBJECT'S ECTS CREDIT LOAD AND E-LEARNING AS DETERMINING FACTORS IN TLP PERCEPTION}

Analyses of the $3 \times 2$ factor interaction, level of ECTS credit load (light-medium-heavy) with the use of e-learning (yes-no), produce very significant evidence. The ECTS credit load factor 
Table 1 | Mean values for the TLP according to year in school and performance level.

\begin{tabular}{|c|c|c|c|c|c|c|c|c|c|}
\hline \multirow{2}{*}{$\begin{array}{l}\text { Year in school } \\
\text { Performance }\end{array}$} & \multicolumn{3}{|c|}{ Years 1 and 2} & \multicolumn{3}{|c|}{ Years 3 and 4} & \multicolumn{3}{|c|}{ Total } \\
\hline & $\mathbf{L}$ & $\mathbf{M}$ & $\mathbf{H}$ & $\mathbf{L}$ & $\mathbf{M}$ & $\mathbf{H}$ & $\mathbf{L}$ & $\mathbf{M}$ & $\mathbf{H}$ \\
\hline$n$ & 11 & 256 & 80 & 8 & 177 & 88 & 19 & 433 & 168 \\
\hline Teaching & $3.60(0.91)$ & $3.74(0.74)$ & $3.84(0.74)$ & $2.95(0.82)$ & $3.77(0.69)$ & $3.86(0.61)$ & $3.33(0.90)$ & $3.75(0.69)$ & $3.86(0.67)$ \\
\hline Learning & $3.49(0.61)$ & $3.66(0.68)$ & $3.87(0.61)$ & $3.15(0.97)$ & $3.74(0.54)$ & $3.82(0.51)$ & $3.34(0.78)$ & 3.69 (0.63) & $3.85(0.56)$ \\
\hline
\end{tabular}

Performance level: $L$, low; $M$, medium; $H$, high.

Table 2 | Mean values for the TLP according to use of e-learning and performance level.

\begin{tabular}{|c|c|c|c|c|c|c|c|c|}
\hline \multirow{2}{*}{$\begin{array}{l}\text { Type } \\
\text { ECTS load }\end{array}$} & \multicolumn{3}{|c|}{ With e-learning } & \multirow[b]{2}{*}{ Total } & \multicolumn{3}{|c|}{ Without e-learning } & \multirow[b]{2}{*}{ Total } \\
\hline & $\mathbf{L}$ & $\mathbf{M}$ & $\mathbf{H}$ & & $\mathbf{L}$ & $\mathbf{M}$ & $\mathbf{H}$ & \\
\hline$n$ & 4 & 97 & 33 & 134 & 9 & 226 & 105 & 340 \\
\hline Teaching & $4.01(0.91)$ & $3.86(0.74)$ & $3.92(0.74)$ & $3.88(0.58)$ & $3.19(0.82)$ & $3.72(0.69)$ & $3.87(0.61)$ & $3.75(0.68)$ \\
\hline Learning & $3.80(0.66)$ & $3.77(0.59)$ & $3.81(0.51)$ & $3.81(0.57)$ & $3.39(0.95)$ & $3.70(0.59)$ & $3.80(0.57)$ & $3.72(0.60)$ \\
\hline
\end{tabular}

Performance level: $L$, low; $M$, medium; $H$, high.

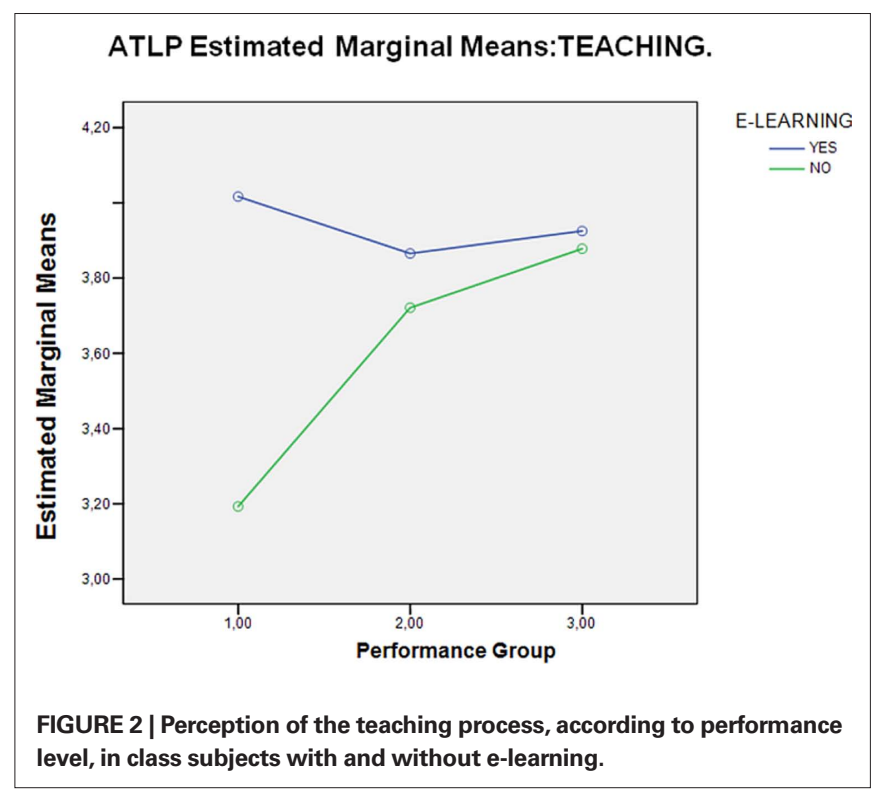

shows a less significant main effect, $F(4.582)=2.14 . p<0.06$, with significant differences in satisfaction with teaching (light and medium $>$ heavy, $p<0.000$ ) and with learning (medium $>$ heavy, $p<0.05)$. A main effect also appeared for the e-learning variable, in its favor, $F(2.290)=4.87, p<0.008$, both for the teaching process, $F(1.291)=7.75, p<0.006$, and the learning process, $F(1.291)=9.50$, $p<0.002$ (see Table 3 ).

However, the most interesting effect was the $3 \times 2$ interaction between the two factors, with a significant general interaction effect, $F(4.582)=5.83, p<0.000$, both for teaching, $F(2.291)=7.75$, $p<0.006$, and for learning, $F(2.291)=4.45, p<0.01$, as seen in Figures 4 and 5. The effect shows clearly that longer TLP are improved with the incorporation of e-learning.

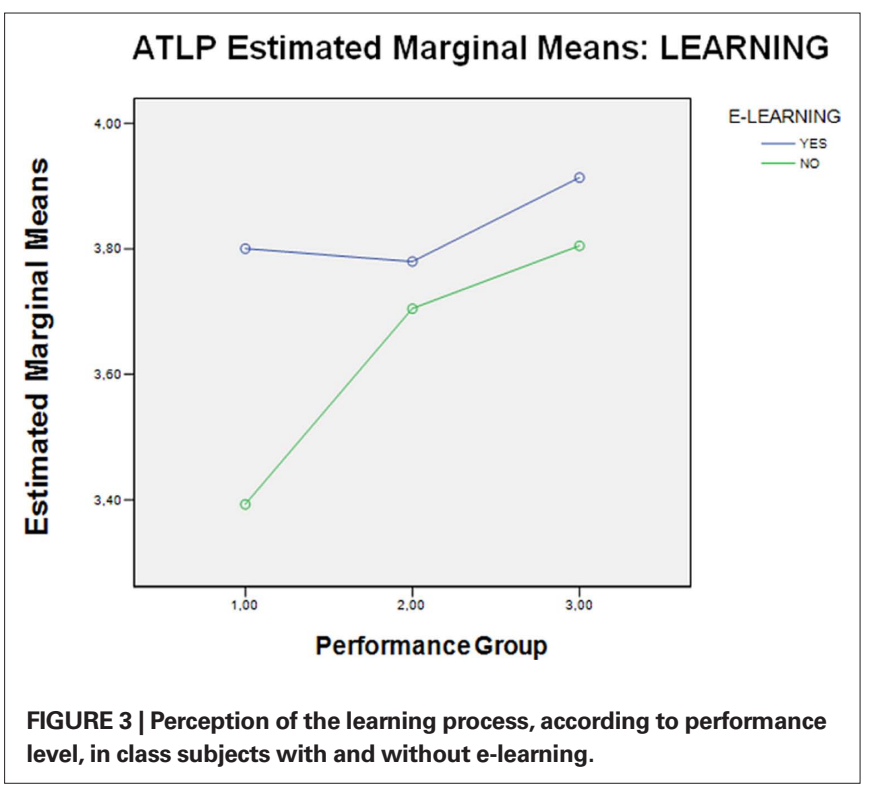

\section{ECTS CREDIT LOAD AND GRADE POINT AVERAGE AS DETERMINING FACTORS IN TLP PERCEPTION}

Analyses of the $3 \times 3$ factor interaction, ECTS credit load (lightmedium-heavy) with students' grade point average (low-mediumhigh), also indicated significant evidence. The ECTS credit load factor shows a statistically significant main effect, $F(4.468)=6.88$, $p<0.000$, on satisfaction with the TLP, $F(2.234)=9.23, p<0.000$, showing significant differences in satisfaction with teaching (light and medium $>$ heavy, $p<0.000$ ) and with learning (medium $>$ heavy, $p<0.000)$. A main effect also appeared for the prior level of performance variable on TLP perception, $F(4.468)=4.87, p<0.008$, both for the teaching process, $F(2.234)=4.13, p<0.01$, and for the learning process, $F(2.234)=4.86, p<0.008$ (see Table 4). 
Table 3 | Mean values forTLP satisfaction, according to ECTS credit load and e-learning.

\begin{tabular}{|c|c|c|c|c|c|c|c|c|}
\hline & \multicolumn{3}{|c|}{ With e-learning } & \multirow[b]{2}{*}{ Total } & \multicolumn{3}{|c|}{ Without e-learning } & \multirow[b]{2}{*}{ Total } \\
\hline & $\mathbf{L}$ & M & $\mathbf{H}$ & & $\mathbf{L}$ & M & $\mathbf{H}$ & \\
\hline Teaching & $4.03(0.57)$ & $3.79(0.47)$ & $4.10(0.63)$ & $3.99(0.58)$ & $3.76(0.76)$ & $3.88(0.54)$ & $3.25(0.93)$ & $3.51(0.85)$ \\
\hline Learning & $3.96(0.57)$ & $3.77(0.46)$ & $4.01(0.61)$ & $3.92(0.56)$ & $3.38(0.90)$ & $3.83(0.53)$ & $3.45(0.86)$ & $3.59(0.77)$ \\
\hline
\end{tabular}

ECTS: L, light; $M$, medium; $H$, heavy.
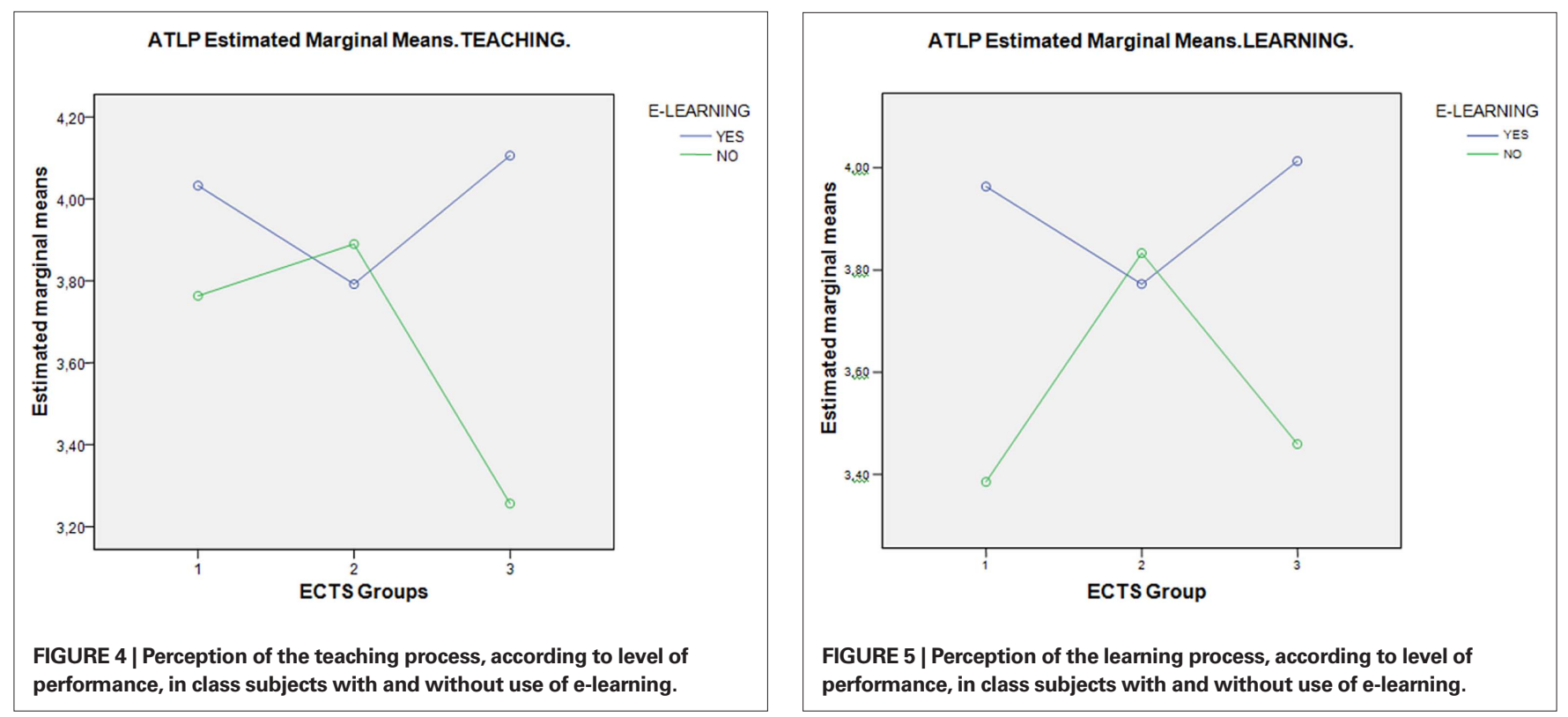

Table 4 | Mean values for the TLP according to ECTS credit load and performance level.

\begin{tabular}{|c|c|c|c|c|c|c|c|c|c|}
\hline \multirow{2}{*}{$\begin{array}{l}\text { ECTS load } \\
\text { Performance }\end{array}$} & \multicolumn{3}{|c|}{ Light } & \multicolumn{3}{|c|}{ Medium } & \multicolumn{3}{|c|}{ Heavy } \\
\hline & $\mathbf{L}$ & M & H & $\mathbf{L}$ & M & $\mathbf{H}$ & $\mathbf{L}$ & M & $\mathbf{H}$ \\
\hline Teaching & $2.88(0.99)$ & $3.80(0.68)$ & $3.59(0.78)$ & $3.73(0.56)$ & $3.86(0.55)$ & $4.24(0.52)$ & $1.73(0.88)$ & $3.15(0.99)$ & $3.29(0.93)$ \\
\hline Learning & $2.86(0.98)$ & $3.78(0.57)$ & $3.58(0.67)$ & $3.28(0.25)$ & $3.73(0.55)$ & $4.09(0.59)$ & $2.86(0.97)$ & $3.25(0.90)$ & $3.85(0.86)$ \\
\hline
\end{tabular}

Performance level: L, low; $M$, medium; $H$, high.

As in the previous case, the $3 \times 3$ interaction between the two factors produced a substantial, significant general interaction effect, $F(8.468)=2.54, p<0.01$, as seen in Figures 6 and 7. A medium process duration and medium ECTS credit load are producing better perception of the process in all cases.

\section{DISCUSSION}

The purposes of this study were to determine the potential factors that influenced the level of satisfaction with the TLP, from the perspective of students participating in the ECTS experience.

The results indicated the weight and variability of different factors that produced significant differences on students' selfperceptions in the Teaching Learning Performance scale. These research findings provided evidence of the significant role of students' grade point average as an influential student's factor in their perception of the TLP. Furthermore, they reinforce and clarified prior studies findings which suggested a general interdependency relationship between students' grades obtained from a certain TLP, and their perception of the level of satisfaction in the process (Doménech et al., 2004; García and San Segundo, 2008; De la Fuente et al., 2010a).

Objective 1 was achieved by demonstrating that the prior average students' performance influenced not only acting as a subsequent variable, but also as a preceding, or presage variable. This means that it can be considered as a relatively stable personal characteristic (De la Fuente and Cardelle-Elawar, 2009), in shaping one's perception 


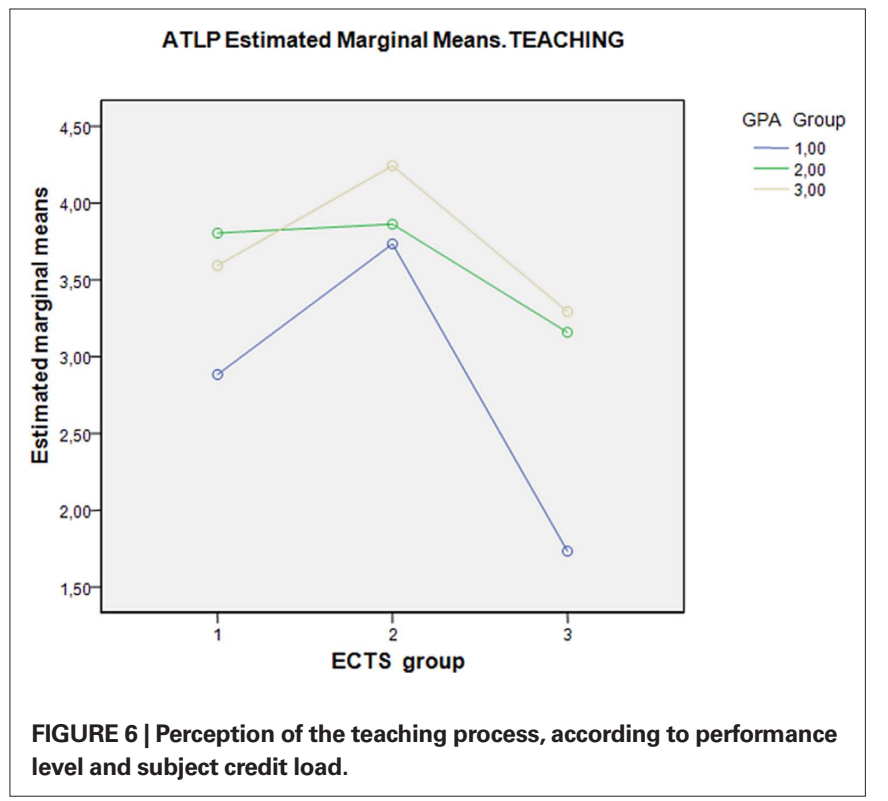

of the TLP. Students with lower performance acknowledge their perceptions of learning and teaching at the lowest level, in contrast with the students who have a higher point grade level.

Objective 2, we recognized from the data that of the e-learning teaching approach played a significant effect on students' perceptions. The results can be interpreted that e-learning provides an unprecedented flexibility and convenience to both learners and instructors. Thus, the substantial impact of learner interaction on their performance becomes critical for educators to improve their instructional pedagogy to assist individual learners to develop their self-regulated skills specially when dealing with lower-performing students (Salinas, 2004; Griful et al., 2005; Coll et al., 2006). Furthermore, in the present study it resulted in significant differences of higher satisfaction in all types of students. Self-regulated learning is increasingly under study, not only in face-to-face education, but also in virtual learning. Most research has focused on face-to-face instructional situations, and revealed the importance of metacognition in general and of selfregulated learning in particular (Bembenutty and Karabenick, 2004). On one hand, some research findings concluded that self-regulated learning strategies optimize the use of cognitive-type operations while learning different discipline areas, while others show that it is possible to improve metacognitive awareness and self-regulation in students while they are learning (McMahon and Ron, 2001; Rogers and Swan, 2001). Research devoted to the study of self-regulated learning online is still quite limited; however, studies show that such regulation is a necessary, important characteristic for students receiving instruction through virtual utilities. One example is the study by Rogers and Swan (2001), which demonstrates that self-regulated learning can be effectively applied to Internet searching behaviors, and indicates some of the strategies used.

Objective 3, the analysis of students' perceptions of the TLP during the third and fourth years, are worth noting. Although the results are not significant, there is some evidence that students with low level of performance also perceived the quality of teaching was at the lower level. This finding is consistent with the effect of year in school on the learning process (Tejedor and García-Valcárcel, 2007).

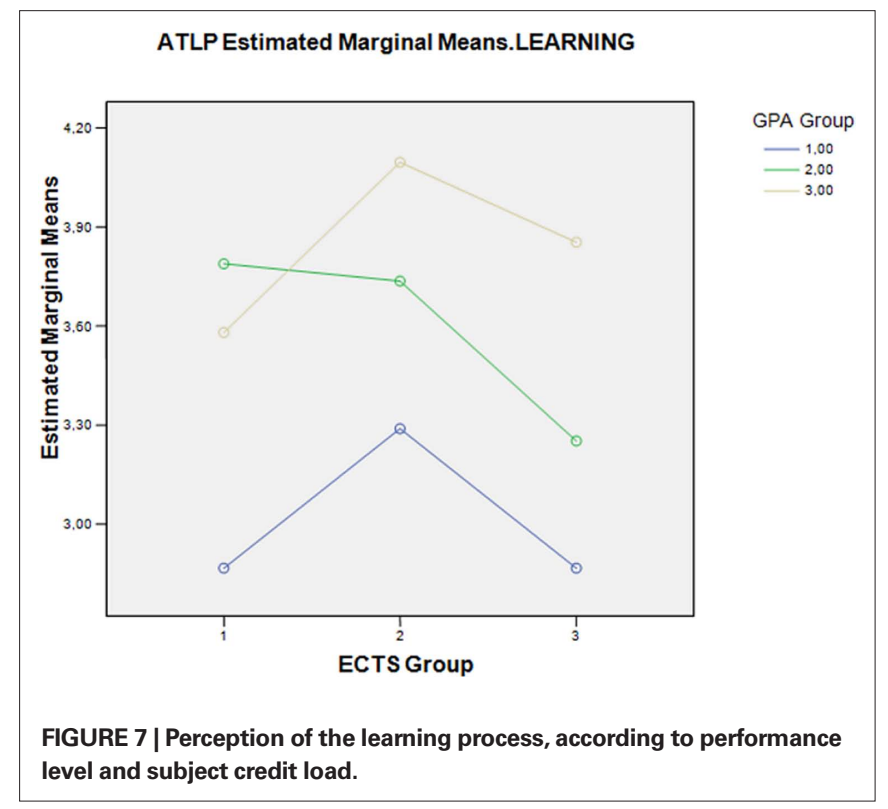

Objective 4. The research findings met objective referring to the role of credit load. The interpretation of the results have shown that short learning periods, with a lesser ECTS load (1-5 ECTS), as well as long periods (9-15 ECTS) received lower ratings of the teaching process. This effect is even more visible when e-learning was not used in the discipline area of study. It appears that short discipline areas reflected more superficial TLPs, or simply insufficient time for processing the learning required to master the content, while a long period of learning or a heavy learning load produces the opposite effect, overtiring the students (Alba and Carballo, 2005). This effect is important in itself, it is more so when placed in interaction with types of student performance. Thus, the combination of low prior performance and courses that are quite short or long, or have a very light or very heavy learning load, is detrimental to the perception of learning and teaching. As for e-learning in conjunction with the learning load, it appears that e-learning can help sustain greater satisfaction in short or long learning processes. However, the perception of learning and teaching falls dramatically when e-learning is not used.

All the aspects mentioned above provided evidence of the factors involved in influencing students' perceptions of the TLP. We believe the results of this study represent a contribution to clarify our (a) understanding of students individual differences in regard to their perceptions of the TLP. (b) These factors have implications for making adjustments to the ECTS experience and also to better understand the role of self-regulation using e-learning. As recent studies suggested teachers using e-learning approaches need to implement a self-regulated learning system with scaffolding support to develop independent learning skills among students. This appears to be essential for content accessibility to students with different academic learning achievement (Kuei-Ping et al., 2010). These findings establish a fairly well delimited profile of factors involved in undergraduate students' perception of the TLP. The significant differences are indicators that this perception depends on the different factors assessed. These factors are therefore important to take into consideration when making adjustments to the ECTS 
experience, and in general at the university level. All the results can be generalized to help us understand how the perception of the teaching and learning is produced at the university level. In addition, the results of this evaluation of the TLP could be generalized to any university.

In conclusion, European universities that are adopting the ECTS system should consider these variables in their current course and evaluation plans - when designing, developing or implementing, and evaluating the processes of teaching and learning. In the design of the TLP, discipline area with a medium ECTS load should be encouraged, with a good deal of e-learning support, and special attention given to the third and fourth years of the degree program. In development of the TLP, satisfaction with learning, and not only with teaching, should be evaluated as a quality criterion and criterion for improvement. As for the end product, when teacher quality is assessed, an important latent variable should be taken into consideration - the grade point average of the students who are making the assessment. This variable, emerging from the DEDEPRO Model, has recurringly shown that students with poorer performance, while recognizing that they execute a poorer learning process, also give lower ratings to their instructors' teaching process (Rinaudo et al., 2003; Doménech et al., 2004; Ruiz et al., 2009).

This research also has limitations that must be noted. Some of these variables should be better defined. For example, we assume that a larger number of learning credits (ECTS) involved a greater burden of learning, but this should be verified according to the subject's content and activities. However, despite these limitations, the study provided research findings that are relevant to understanding the factors that influenced students' level of satisfaction with the TLP.

The implications of these variables, especially in types of students, are critically important to better understand the need for self-regulating training and (a) in designing e-learning instruction. Dabbach and Kitsantas (2004) stated that it is essential in student-centered approaches, where students assume as primary responsibility for their learning. Where as in face-to-face classroom settings, the instructor exercises considerable control over the student learning process and he or she is able to monitor students' attention. (b) The DEDEPRO model provides flexibility

\section{REFERENCES}

Abar, B., and Loken, E. (2010). Selfregulated learning and self-directed study in a pre-college sample. Learn. Individ. Differ. 20, 25-29.

Alba, C., and Carballo, R. (2005). Viabilidad de las propuestas metodológicas para la aplicación del crédito europeo por parte del profesorado de las universidades españolas, vinculadas a la utilización de las TIC en la docencia y la investigación. [Viability of proposed methods for Spanish university professors' application of the European credit, linked to the use of ICTs in teaching and research.] Rev. Educ. 337, 71-97.

Bembenutty, H., and Karabenick, S. A. (2004). Inherent association between academic delay of gratification, future to develop instruction tailored to both approaches (face-to-face and e-learning). This can be a challenge and at the same time a reward by creating communities of learning to educate ourselves to better teach to meet ECTS standards. (c) Taking into account students' perceptions of the TLP to be more effective in evaluating the TLP in university evaluation processes, and this has not been sufficiently taken into account in ECTS experimentation. In the long run, they can affect processes that evaluate teaching quality, and the quality of the university itself. In the worst case, teachers could be subject to an ongoing adjustment process in response to low-performing students, making multiple adjustments with little likelihood of changing these students' perception of the teaching or their inadequate learning process. Ultimately, a cyclical process would ensue, creating a synergy that is difficult to break: (1) students with low prior performance; (2) TLPs adjusted toward this typology of student; (3) low assessment of teaching; (4) low assessment of the university.

Finally, every university must pursue excellence, balanced with the social function that it has been assigned. Thus, attracting talented pupils who have a good record of learning and prior performance must become a strategic priority. In order to carry out excellent teaching processes, excellent learning processes are also needed. The teaching-learning binomial cannot be broken nor should it become unbalanced in favor of one of its two poles. Teaching cannot take place in a vacuum, irrespective of learning, nor can teaching quality be assessed without taking into account the learning process and the typology of students. The quality of teaching is necessarily filtered through the quality of learning, so that the two in conjunction may produce a final, quality achievement product.

\section{ACKNOWLEDGMENTS}

This work was carried out under the auspices of: (1) RD\&I Project ref. BSO2003-06493. Improving self-regulated learning in university students through online regulatory teaching strategies. Ministry of Science and Technology and European Social Fund (2003-2006), Spain. (2) RD\&I Project ref. SEJ2007-66843/educ. Assessing improvement in the teaching-learning process and assessment of competencies in the European Higher Education Area: Model and Protocols. Ministry of Education and Science, European Social Fund (2007-2010). Spain. y disposición previa del alumno universitario. [University students' use of information and communication technologies and their prior disposition.] Psicol. Educ. 13, 65-78.

Caballero, C. C., Abello, R., and Palacios, J. (2007). Relación del bournout y el rendimiento académico con la satisfacción frente a los estudios en estudiantes universitarios. [Relationship of burnout and academic performance to satisfaction with studies in university students.] Avances en Psicología Latinoamericana 25, 98-111.

Cardelle-Elawar, M., and Sanz de Acedo Lizarraga, M. L. (2010). "Selfregulation and the WebQuest: a model to transform teacher education," in International Handbook on
Applying Self-Regulated Learning in Different Settings, eds J. De la Fuente and M. A. Eissa (Almería: Education \& Psychology I + D + i, e-Publishing Series), 425-447.

Case, J., and Gunstone, R. (2002). Metacognitive development as a shift in approach to learning: an in-depth study. Stud. High. Educ. 27, 459-470.

Coll, C., Mauri, T., and Onrubia, J. (2006). Análisis y resolución de casos-problema mediante el aprendizaje colaborativo. [Analysis and caseproblem solving through collaborative learning]. In Antoni Badia (coord.). Enseñanza y aprendizaje con TIC en la educación superior [online monograph]. Revista de Universidad y Sociedad del Conocimiento 3. Accessed on July 242010 at http://www.uoc. 
edu/rusc/3/2/dt/esp/coll_mauri_ onrubia.pdf

Coll, C., Rochera, M. J., Mayodormo, R. M., and Naranjo, M. (2007). Continuous assessment and support for learning. An experience in educational innovation with ICT support in higher education. Electron. J. Res. Educ. Psychol. 5, 783-804.

Correa, J. M., and Paredes, J. (2009). Cambio tecnológico, usos de plataformas de e-learning y transformación de la enseñanza en las universidades españolas: la perspectiva de los profesores. [Technological change, use of e-learning platforms and transformation of teaching in Spanish universities: the teachers' perspective]. Revista de Psicodidáctica 14, 261-277.

Dabbach, N., and Kitsantas, A. (2004). Improving self-regulation, learning strategy use, and achievement. Int. J. Artif. Intell. Educ. 16, 101-130.

De la Fuente, J. (2009). Protocol for Evaluating the Teaching-Learning Process in the European Space for Higher Education. Almería: Education \& Psychology I + D + i, e-Publishing Series.

De la Fuente, J. (in press). "Implications of the DEDEPRO model for interactive analysis of the teaching-learning process in higher education," in Higher Education in a State of Crisis, ed. R. M. Texeira (New York: NOVA Publishers).

De la Fuente, J., and Cardelle-Elawar, M. (2009). Research on action-emotion style and study habits: effects of individual differences on learning and academic performance of undergraduate students. Learn. Individ. Differ. 19, 567-576.

De la Fuente, J., and Eissa, M. A. (eds). (2010). International Handbook on Applying Self-Regulated Learning in Different Settings. Almería: Education \& Psychology I+ D + i, e-Publishing Series.

De la Fuente, J., and Justicia, F. (2007). The DEDEPRO model for regulating teaching and learning: recent advances. Electron. J. Res. Educ. Psychol. 5, 535-564.

De la Fuente, J., Justicia, F., and Berbén, A. (2005a). Enfoques de aprendizaje, percepción delteaching-learning process y rendimiento de universitarios. [Approaches to learning, perception of the teaching-learning process and performance of university students.] Rev. Psicol. Educ. 1, 87-102.

De la Fuente, J., Justicia, F., and GarcíaBerbén, A. B. (2005b). An interactive model of regulated teaching and selfregulated learning. Int. J. Learn. 12, 217-225.

De la Fuente, J., Martínez-Vicente, J. M., Peralta, F. J., and García-
Berbén, A. B. (2010a). Percepción del proceso de enseñanza-aprendizaje y rendimiento académico en diferentes contextos instruccionales de la Educación Superior. [Perception of the teaching-learning process and academic performance in different instructional contexts of higher education.] Psicothema 22, 806-812.

De la Fuente, J., Sander, P., Justicia, F., Pichardo, M. C., and García-Berbén, A. B. (2010b). Validation Study of the Scale for Assessment of the TeachingLearning Process, Student Version (ATLP-S). Electron. J. Res. Educ. Psychol. 8, 815-840.

De la Fuente, J., Pichardo, M., Justicia, F., and García-Berbén, A. B. (2008). Enfoques de aprendizaje, autorregulación y rendimiento en tres universidades europeas. [Learning approaches, self-regulation and achievement at three European universities.] Psicothema 20, 705-711.

De la Fuente, J., and Trujillo, T. M. (2008). e-EEES. [Electronic utility for assessment in the European Higher Education Area.] Almería: Education \& Psychology I + D + i, e-Publishing Series.

De Miguel, M. (Coord) (2006). Metodologías de. (enseñanza)y aprendizaje para el desarrollo de competencias. Orientaciones para el profesorado universitario ante el Espacio Europeo de Educación Superior. [Teaching and Learning Methodologies for Competency Development. Guidelines for University Professors in the European Higher Education Area.] Madrid: Alianza Editorial.

De Miguel, M., and Arias, J. M. (1999). La evaluación del rendimiento inmediato en la enseñanza Universitaria. [Immediate performance assessment in university education.] Rev. Educ. 320, 353-377.

Doménech, F., Jara, P., and Rosel, J. (2004). Percepción del proceso de enseñanza-aprendizaje desarrollado en Psicoestadística I y su incidencia en el rendimiento. [Perception of the teaching-learning process in Psychology Statistics I and its effect on performance.] Psicothema 16, 32-38.

García, M. M., and San Segundo, M. J. (2008). "El rendimiento académico en el primer curso universitario. [Academic performance in first-year university students]," in X Jornadas de la Asociación de Economía de la Educación. Accessed on July 24, 2010 at http://www.pagina-aede.org/Murcia/ E02.pdf

García-Berbén, A. B., Pichardo, M. C., and Dela Fuente, J. (2007). Relaciones entre preferencias de la enseñanza y enfoques de aprendizaje de los universitarios. [Relationships between university students' teaching preferences and their approaches to learning.] Infanc. Aprendiz. 30, 537-550.

Griful, E., Gibert, J., and Sallan, J. M. (2005). "Un modelo de blended learning en la Universidad Politécnica de Catalunya: la docencia semipresencial de la titulación de Ingeniería en Organización Industrial en la ETSEIT [A blended learning model at Catalonia Polytechnic University: the Industrial Organization Engineering degree at ETSEIT]," in IX Congreso de Ingeniería de Organización, Gijón, 8-9 September 2005.

Heikkila, A., and Lonka, K. (2006) Studying in higher education: students' approaches to learning, selfregulation and cognitive strategies. Stud. High. Educ. 31, 99-117.

Kuei-Ping, S., Hung-Chang, C., ChiihYung, C., and Tai-Chien, K. (2010). The development and implementation of scaffolding-based self-regulated learning system for e/m-learning. Educ. Technol. Soc. 13, 80-93.

Mahdizadeh, H., Biemans, H., and Mulder, M. (2008). Determining factors of the use of e-learning environments by university teachers. Comput. Educ. 51, 142-154.

McMahon, M., and Ron, O. (2001). "Promoting self-regulated learning in an on-line environment," in Presentation given at Proceedings of the 13th World Conference on Educational Multimedia, Hypermedia and Telecommunications, Tampere, Finland, June 25-30.

Méndez, C. (2005). La implantación del sistema de créditos europeo como una oportunidad para la innovación y mejora de los procedimientos de enseñanza/aprendizaje en la universidad. [Implementation of the European credit system as an opportunity for innovation and improvement of teaching-learning procedures at university.] Revista Española De Pedagogía 63, 43-62.

Ministry of Education. (2010). Programa Docentia. [National program on Teaching.] Spanish Ministry of Education. Accessed July 23, 2010 at http://www.aneca.es/actividadesevaluacion/evaluacionenseñanzas/ docentia.aspx

Montil, M., Barceló, O., Bielsa, R., and Oliván, J. (2007). Análisis del trabajo no presencial utilizando un enfoque ECTS. [Analysis of distance studies using an ECTS approach.] Revista Complutense de Educación 18, 183-198.

Rinaudo, M.C., Chiecher, A., and Donolo, D. (2003). Motivación y uso de estrategias en estudiantes universitarios. Su evaluación a partir del Motivated Strategies Learning Questionnaire. [Motivation and strategy use in university students. Assessment based on the Motivated Strategies Learning Questionnaire.] Anales de Psicología 19, 107-119.

Rogers, D. M., and Swan, K. (2001). "An investigation of components in Corno and Mandinach's self-regulated model applied to Internet navigation," in Annual Meeting of the American Educational Research Association, Seattle, April 10-14.

Ruiz, F., Molina, M., Lupiáñez, J. L., Segovia, I., and Flores, P. (2009). Mathematics primary teachers training at the University of Granada: an adaptation of EHEA. Electron. J. Res. Educ. Psychol. 7, 425-454.

Salanova, M., Martínez, I., Bresó, E., Llorens, S., and Grau, R. (2005). Bienestar psicológico en estudiantes universitarios: facilitadores y obstaculizadores del desempeño académico. [Psychological well-being in university students: facilitators and hindrances to academic performance.] Anales de Psicología 21, 170-180.

Salinas, J. (2004). Cambios metodológicos con las TIC. Estrategias didácticas y entornos virtuales de enseñanzaaprendizaje. [Methodology changes using ICTs. Teaching strategies and virtual teaching-learning environments.] Bordón: Revista de Orientación Pedagógica 56, 469-481.

Schunk, D. H., and Zimmerman, B. J. (eds). (2008). Motivation and Self-Regulated Learning. New York: Routledge.

Solanes, A., Nuñez, R., and Rodríguez, J. (2008). Elaboración de un cuestionario para la evaluación de competencias genéricas en estudiantes universitarios. [Preparing a questionnaire for assessment of generic competencies in university students.] Apuntes de Psicología 26, 35-49.

Tejedor, F. J., and García-Valcárcel, A. (2007). Causas del bajo rendimiento del estudiante universitario (en opinión de los profesores y alumnos). Propuestas de mejora en el marco del EEES. [Causes of low performance in the university student (in the opinion of teachers and students). Improvement proposals within the EHEA framework.] Rev. Educ. 342, 443-473.

Tirado, S., Cañadas, I., and Núñez, R. (2006). El docente universitario en el espacio Europeo de Educación Superior: Nuevos retos, nuevos mecanismos de evaluación. [The university instructor in the European Higher Education Area: new challenges, new assessment mechanisms.] 
Revista de Psicología Social Aplicada 16, 81-95.

Zimmerman, B. J. (2008). Investigating self-regulation and motivation: historical background, methodological developments, and futures prospects. Am. Educ. Res. J. 45, 166-183.

Zimmerman, B. J., and Martínez-Pons, M. (1988). Construct validation of a strategy model of student self-regulated learning. J. Educ. Psychol. 80, 284-290.
Zusho, A., and Pintrich, P. (2003). Skill and hill: the role of motivation and cognition in the learning of college chemistry. Int. J. Sci. Educ. 25, 1081-1094.

Conflict of Interest Statement: The authors declare that the research was conducted in the absence of any commercial or financial relationships that could be construed as a potential conflict of interest.
Received: 29 September 2010; paper pending published: 15 October 2010; accepted: 10 February 2011; published online: 03 March 2011.

Citation: De la Fuente J, Cardelle-Elawar M, Peralta FJ, Sánchez MD, MartínezVicente JM and Zapata L (2011) Students' factors affecting undergraduates' perceptions of their teaching and learning process within ECTS experience. Front. Psychology. 2:28. doi: 10.3389/fpsyg.2011.00028
This article was submitted to Frontiers in Educational Psychology, a specialty of Frontiers in Psychology.

Copyright $\odot 2011$ De la Fuente, CardelleElawar, Peralta, Sánchez, Martínez-Vicente and Zapata. This is an open-access article subject to an exclusive license agreement between the authors and Frontiers MediaSA, which permits unrestricted use, distribution, and reproduction in any medium, provided the original authors and source are credited. 


\section{APPENDIX}

Items that make up the ATLP-S (De la Fuente and Justicia, 2007):

T1. The general approach is useful in my educational development.

T2. The teacher explained the rationale for what we were learning.

T3. Teaching objectives were clear.

T4. The teaching objectives helped me in building my own knowledge.

T5. The teaching content was appropriate.

T6. Course content which addressed facts and concepts seemed appropriate to me.

T7. Course content which taught procedures seemed appropriate to me.

T8. Course content which addressed attitudes, values and rules seemed appropriate to me.

T9. The teacher encouraged my involvement in the learning process.

T10. The teaching approach encouraged relevant, useful learning.

T11. Materials used in the course/module were appropriate.

T12. The time dedicated to each topic was appropriate.
T13. The teacher's behavior (interaction, attitude, etc.) was appropriate.

T14. think the assessment strategies used were appropriate.

T15. In general, the teaching process was appropriate.

L16. I understood the general structure of the course/module.

L17. The importance of what we were learning was clear to me.

L18. I had clear learning objectives.

L19. My learning objectives helped me build my own knowledge.

L20. I was able to sort out the content to be learned.

L21. I have adequately worked through the facts and concepts to be learned in this course/module.

L22. I have put into practice the procedures to be learned in this course/module

L23. I have acquired the attitudes, values and rules to be learned in this course/module.

L24. I was actively involved in the learning process.

L25. I adequately planned and regulated my own learning.

L26. The resource materials I used (reference books, etc.) were sufficient.

L27. The time I dedicated to learning each topic was adequate.

L28. I had regular attendance, that is, I attended most classes.

L29. I used appropriate self-evaluation strategies during the learning process.

L30. In general, my learning process was appropriate. 